\title{
Application of Modern Education in Physical Education Teaching Resources
}

\author{
Xinru LIU \\ Department of Physical Education \\ Hubei University of Medicine \\ Shiyan, Hubei, China, 442000
}

\author{
Guanghui XIE \\ Department of Physical Education \\ Hubei University of Medicine \\ Shiyan, Hubei, China, 442000
}

\begin{abstract}
The modern educational technology in teaching is a very common thing, the various disciplines are often used in sports as a part of quality education, and the teaching development should also be combined with the characteristics of the times, to meet the requirements of the times, use modern product to the serve Physical Education. Sports disciplines need to research and analysis for their subject characteristics and provide basis for optimizing the classroom, to establish a new open sports teaching method, to make teaching become more efficiency. The development of modern society provides a richer sports teaching resources, sports teaching philosophy is evolving, keeping up with the times, thus changing the teaching mode, teaching reform, combined with modern physical education resources applications, so teaching can train students more comprehensive, to achieve teaching objectives and provide help to improve physical fitness and students' literacy.
\end{abstract}

Keywords- Modern Physical Education; Physical Education Resources; students' comprehensive training

\section{INTRODUCTION}

Modern educational resources is one of the important resources of modern human existence and social development, it is one of the fundamental conditions for sustainable development education, promoting economic development and social progress of civilization. The socalled modern education resources, is the sum of the natural resources on education and social resources. Natural Resource Education include: natural conditions of education, such as land, natural geography, location, educational environment, such as housing, facilities, venues, social, educational and cultural atmosphere, community environmental conditions, human (untapped manpower), humanities environment. Community education resources include: human resource education (already developed human resources), education funding, educational technology, educational experience, educational traditions, educational organization structure, systems and education scale system of education. Education is courses that theoretical and practical is both strong, but also very close combination of social practice. In practice, it is difficult to separate social education resources with natural education resources. Therefore, for convenience, when this article discusses the concept of educational resources, in general divide education resources into the development of education for the environment, human resources, capital, technology and other resources to the elements. The advent of computers and network education system, education on new ideas, new methods, new technologies, especially the emergence of computer networks and other modern information technology, mankind created a virtual teaching space, and the formation of unprecedented ideological and cultural education. Large-capacity, multi-information and high efficiency characteristics of multimedia education are gradually replace the traditional mode of education. The maps, text, sound, image, and other media information come into the classroom has become a trend in modern education. Multimedia Courseware is a sign of modern educational technology product development, multimedia presentations will combine with a variety of multimedia courseware material and integrated in education-related courseware, teaching rich content while improving the students' interest, so as to further improve the quality of teaching.

\section{CATEGORY OF EDUCATION RESOURCES}

\section{A. Environmental education resources}

Environmental education resources, includes natural and social environment of education. Natural Resource Education is where the relationship between man and his natural. People can not exist without nature; the field of education must at certain natural surroundings. Although during the human development, education detached natural phenomenon, but as people deepen understanding of nature, people return to nature. "Although the truth of how people deal with the relationship between people and the natural environment is not new, but in practice, the thinking of "harmony between man and nature " can't be full implemented. For example, the broader development plans of education, the base choice of education, school design and construction, campus planning, greening and beautification, etc., and do not reach the extent of expected benign. It often occurs due to the needs of social and economic development, urban construction planning, school consolidation needs to scale or forced relocation due to various reasons, the demolition or renovation often, artificially change plan is not 
home, the environment is not stable, waste of resources, pollution and other campus issues.

\section{B. Education's human resource}

HR strategy is a strategic issue that many countries and units are focused on. Human resources and education includes human untapped manpower and already found manpower. Strictly speaking, this division is not very scientific, because the development and utilization of human resources is a process that constantly adapt to the economic development education's evolving social progress, so the already developed human resources can also change based on changed conditions continue to develop, while the untapped human resources is not no development. In education, it is customary to say that human resources are educators and educated manpower. Education has always been the subject of social and educational development. From the perspective of overall development, the human education is much more than just students and teachers, people who left school and went into the community may still get education. In particular, modern education is essentially a lifelong education. Though some people are not school teachers they still possible to become educators. In particular, modern society is the information society; education has rendered a major trend of society, diversity, three-dimensional network.

\section{Financial resources of education}

Education's financial resources mainly refer to country, including funding provided by community for education (including educational material conditions). The purpose of state and community provide funding for education is to nurture talent consumption through education, promote the progress of education, to make sustainable economic development and social development. If this "special consumer" is not reasonable, then, it will not be able to train more national and social manpower to meet the needs of people, and it can not meet the growing demand for higher education, thus impeding the sustainable development of education, also hindered the development of the economy and society. Social capital is a tremendous force to be reckoned with, as long as we effectively in accordance with market rules, with appropriate policies and effective measures, then it will be more and more social capital investment in education.

\section{EXISTING PROBLEMS}

\section{A. Multimedia courseware design should be relatively uniform with technical standards}

We now lack of effective, authoritative guidance in the design of multimedia courseware production process, teachers due to their subject knowledge limitations, when they create courseware, tend to use their own familiar, handy but not the best software to make, and such software in various categories, the software designer has their own strengths, have a strong tendency, some emphasis on audio effects, video effects and some emphasis on heavy chart classification. Such as animation software, there are 3D max,
Macromedia Flash, Maya, etc., they are designed to handle a variety of animation; it will be difficult for a teacher to judge and choose subjects. Currently in a region to develop a standard, apparently there are certain difficulties, but in an industry, a school is entirely possible. In the school system, combined with an industry professional disciplines and industry characteristics, the school has the technical advantage; it's possible to preferably a standard.

\section{B. Combine network professional technical staff with is also a weakness}

Our teachers in the multimedia courseware design and production process, lack of support and technical personnel, this is due to teachers subjective reasons but also modern system's loss. From the current system and management point of view, school networks and educational technology department is to undertake school digital operation, management and maintenance of passive extensive management, network technology sector and the teaching departments, faculties are parallel rather than cross-sector operations department. Cooperation is passive; it is a personal initiative to achieve. It's not complete by scientific management and institutional norms. On the one hand, it is the rapid development of network technology, multimedia technology, the rapid increase of the level of professional and technical personnel. The other is due to the limitations of computer skills of teachers, the multimedia courseware design and production levels delays pace with the rapid development of the growing educational technology, delays the results of current educational technology with development.

\section{Multimedia technology is in an important position in the modern educational technology in the occupied areas}

We have need for multiple levels of multimedia courseware design ideas, techniques, etc. and give the necessary attention. Multimedia courseware must first meet teaching law, it is designed to follow the laws of the curriculum design, curriculum adaptation control system components, knowledge of proper representation in the discipline to follow the premise of teaching law at the correct representation of subject knowledge within the context of scientific text, graphics, animation, audio, video and other multimedia information organic integration as a whole, the system around the course materials designed to be integral. It's fully demonstrated its vitality in teaching. In the design of multimedia courseware production, there are still some fundamental problems, low levels of courseware design, due to the teaching of modern management concepts of education in pursuit of promoting the process of one-sided classroom and using the number of modern educational technology and compulsory subjects' provisions multimedia ratio. 


\section{EdUCATION RESOURCES IN PHYSICAL TEACHING}

\section{A. Strengthen business learning, change thinking and comprehensive implement the modernization of Physical Education}

IT is very fast development modern society, the application is very large, so the development of modern sports teaching correspondingly faster. Modern educational technology for students can be intuitive, vivid display, increasing the fun of teaching to enhance the enthusiasm of the students, so that they can enhance critical thinking skills, learn to solve learning difficulties, to enhance students' learning ability has offered helped. In addition, teachers can train students through the Internet and other modern technology, self-learning and cooperative learning, so that students learn more proactive, expand their horizons, acquire practical skills. Modern Educational Technology for Physical Education provides a way of integration of resources, for sports teaching model provides a way to change; the resulting effect is very good.

\section{B. Provides thematic activities, changes assessment mechanism and enhance students' academic sports subject}

Physical education teachers need to cultivate students' disciplinary literacy. Each discipline has its own literacy requirements, only to meet the requirements truly grasp the essence of the discipline to be able to learn this discipline. Physical education needs to introduce sports knowledge to enable students to develop an understanding of sports, to know the use of sports, learn sports skills in later life and enhance physical activity, improve their physical and become a more comprehensive talent. The application of modern technology, sports teaching learning environment for students has been optimized, the higher the students' skills, the higher the learning ability. Therefore, student's sports disciplinary literacy has improved accordingly. In physical education activities, teachers use modern means of education for students to give sports action essentials show, and then let the students themselves try to figure out and learn, returned classroom to students, teachers stand beside and guide such classroom activities more freely, students are able to learn independently and enhance students' enthusiasm.

\section{Integration of educational resources, optimize teaching structure, and highlight the characteristics of Physical Education}

The application of modern educational technology in the classroom teaching sports did receive good teaching effect, greatly improving the efficiency of Physical Education, optimizing the teaching structure and active classroom atmosphere, students like this teaching mode. Use modern educational technology to integrate physical education; highlight the characteristics of physical education. Play the role of modern educational resources, scenically highlight the difficulties. Many physical education curriculums are process learning, so during these processes, it is very difficult to teach motor skills. Due to the short time that teachers present in action during the demo, coherent and strong, students' representation thinking is difficult to form, and the learning outcomes are poor. Especially when those more dangerous action, or older teachers demonstrate these difficult course of action, teachers can only use language to describe, it is difficult to achieve the desired effect. If teachers use animation, it will show the details of courseware to help students clearly understand all aspects of technology essentials. By controlling the playback speed, or pause playback and other operations, so students can have a more careful observation, highlighting the characteristics of Physical Education. Play the superiority role of sports in enhancing the effectiveness of Physical Education.

\section{CONCLUSIONS}

Since it is an element of physical education teaching quality education, they should be quality education for the direction to carry out, for the overall development efforts of students, the time when students' sports skills upgrading but also trained for students' psychological and physical qualities, this allows students to truly achieve all-round development. Relatively due to the fast development of modern science and technology level, there are rich modern sports teaching resources, and a lot of modern teaching methods are widely used in physical education teachers, the use of modern teaching methods can make some of the abstract handled more figurative, making the sports teaching content becomes more vivid and easy to understand, students learn faster can firmly grasp, as well as enhance the ability to solve problems and achieve comprehensive development.

\section{References}

[1] Si Wenjie modern education resources in the Physical Education Teaching [J] Chinese educational technology and equipment, 2013,04: 107-108.

[2] Guo Xiaoping modern educational resources in Sports Teaching [J] China Modern Educational Equipment, 2013,04: 30-31.

[3] Jin Ning of modern educational resources in Sports Teaching [J] enterprise Herald, 2014,14: 188-189.

[4] Wang Lihui modern educational resources in Sports Teaching [J] Science and Technology Information, 2014,32: 139.

[5] Zhang langang The development and utilization of modern educational resources [J] Hefei University of Technology (Social Sciences), 2002,04: 69-73.

[6] Bian Zhanli accounting legislation in Physical Education should use modern educational resources $[\mathrm{J}]$ Chinese and foreign entrepreneurs, 2014,21: 135 